\title{
Formulation and Optimization of Gastric Bioadhesive Tablets of Diltiazem Hydrochloride using Central Composite Design
}

\author{
Saurabh Sharma ${ }^{1^{*}},{\text { Arun } \mathrm{Nanda}^{2} \text { and Lalit Singh }}^{3}$ \\ ${ }^{1}$ Department of Pharmacy, Vivek College of Technical Education, Bijnor, ${ }^{2}$ Department of Pharm Sci, M D University, Rohtak, \\ ${ }^{3}$ SRMS CET, Bareilly, India
}

*For correspondence: Email: saurabhmpharm@rediffmail.com; Tel: +919927026893

Received: 5 September 2013

Revised accepted: 2 October 2013

\begin{abstract}
Purpose: To develop bioadhesive tablets of diltiazem hydrochloride with a unique combination of bioadhesion and drug release.

Method: Tablets were prepared by physical blending of diltiazem hydrochloride with two polymers, viz., carbopol and hydroxylpropyl methyl cellulose in different ratio along with other excipients. $A 3^{2}$ central composite design was employed to optimize the formulations on the basis of phycochemical properties, bioadhesive strength (measured as force of detachment from gastric mucosa) and in vitro drug release. HPMC K 4M and Carbopol 934P were taken as the independent variables. Contour plots were drawn and optimum formulations were selected by feasibility and grid searches.

Results: The tablets showed excellent bioadhesive strength which varied from 7.6 to $21 \mathrm{~g}$. Both polymers had effect on the bioadhesive strength of the tablets and maximum bioadhesion was observed at the highest level of both the polymers. The drug release from the formulation varied from 79.74 to $94.54 \%$ in $12 \mathrm{~h}$. The diffusion exponent $(n)$ of Korsmeyer-Peppas model ranged from 0.491 to 0.658 which indicates the mechanism of drug release was anomalous transport; the diffusion exponent $(n)$ increased with increase in the amount of either polymer in the bioadhesive tablet.

Conclusion: Floating bioadhesive tablets of diltiazem hydrochloride with good bioadhesion and controlled release characteristics is feasible.
\end{abstract}

Keywords: Drug delivery, Gastroretentive, Bioadhesive, Diltiazem, Central composite design.

Tropical Journal of Pharmaceutical Research is indexed by Science Citation Index (SciSearch), Scopus, International Pharmaceutical Abstract, Chemical Abstracts, Embase, Index Copernicus, EBSCO, African Index Medicus, JournalSeek, Journal Citation Reports/Science Edition, Directory of Open Access Journals (DOAJ), African Journal Online, Bioline International, Open-J-Gate and Pharmacy Abstracts

\section{INTRODUCTION}

Diltiazem hydrochloride (DTZ) is a calcium channel blocker belonging to the benzothiazepine family. It is widely prescribed for the treatment of hypertension and angina. It has an elimination half-life of $3.5 \mathrm{~h}$ and an absorption zone from the upper intestinal tract. Efficacy of the administered dose may get diminished due to incomplete drug release from the device above the absorption zone. DTZ requires multiple daily drug dosage in order to maintain adequate plasma concentrations [1]. A suitable drug delivery system can improve controlled delivery of a drug exhibiting an absorption window by continuously releasing the drug for a prolonged period before it reaches the absorption site, thus ensuring its optimal bioavailability $[2,3]$.

Various approaches including floating systems, bioadhesive systems, swelling and expanding 
systems and high density systems have been successfully employed to improve the gastric residence time of a delivery system [4,5]. Though highly efficient for gastroretention, floating systems suffer from a major disadvantage that they are effective only when the fluid level in the stomach is sufficiently high. However, as the stomach empties and the tablet is at the pylorus, the buoyancy of the dosage form may be impeded [6]. This serious limitation can be overcome by making the system eventually adhere to the mucous lining of the stomach wall.

Mucoadhesion has been an extensively adapted approach for achieving site-specific drug delivery through the amalgamation of mucoadhesive polymers within pharmaceutical formulations along with the active pharmaceutical ingredient (API). Mucoadhesive materials are hydrophilic macromolecules containing numerous hydrogen bond forming groups. The mechanism by which mucoadhesion takes place has been said to be in two stages: the contact (wetting) stage followed by the consolidation stage (establishment of adhesive interactions) [7].

The objective of the current study was to develop bioadhesive tablets of diltiazem hydrochloride and optimize their bioadhesive and drug release characteristics using the benefits of central composite design methodology [8].

\section{EXPERIMENTAL}

\section{Materials}

Diltiazem hydrochloride, Carbopol 934P and HPMC K4M were obtained as gifts from Modi Mudi Pharmaceuticals, Meerut and all other chemicals used were of analytical grade.

\section{Preparation of Bioadhesive Tablets}

Different bioadhesive tablet formulations of diltiazem hydrochloride were formulated using varying amount of two polymers (carbopol and HPMC) and Microcrystalline cellulose as diluent, which does not interfere with the floating property of the tablets due to its low bulk density [9] along with fixed quantity of talc and magnesium stearate as glidant and lubricant respectively. All ingredients, except magnesium stearate, were passed through $200 \mu$ aperture sieve and then mixed for $20 \mathrm{~min}$. Finally, Magnesium stearate was added into powder blend as a lubricant and mixed for an additional $3 \mathrm{~min}$ before compaction process. Then, $360 \mathrm{mg}$ tablets containing $90 \mathrm{mg}$ diltiazem hydrochloride were prepared by a lab press [8]. The tablet formulations are shown in Table 1.

Table 1: Composition of bioadhesive tablets of diltiazem $\mathrm{HCl}$

\begin{tabular}{ll} 
Ingredient & Quantity \\
\hline Diltiazem Hydrochloride & $90 \mathrm{mg}$ \\
Carbopol 934P & $60-100 \mathrm{mg}$ \\
HPMC K4M & $90-150 \mathrm{mg}$ \\
Magnesium stearate & $1 \%$ \\
Talc & $3 \%$ \\
Microcrystalline cellulose & q.s. to $360 \mathrm{mg}$ \\
\hline
\end{tabular}

\section{Experimental design}

A central composite design (CCD) for two factors at three levels each $(\alpha=1)$ was selected to optimize the varied response variables. The two factors, viz., polymer $\mathrm{X}_{1}(\mathrm{CP})$ and polymer $\mathrm{X}_{2}$ (HPMC) of each polymer bland, were varied as required by the experimental design and the factor level were suitably coded (Table 2). The extent of drug release in $12 \mathrm{~h}\left(\mathrm{Q}_{12}\right)$, time to release $60 \%\left(\mathrm{t}_{60 \%}\right)$ and bioadhesive strength (BS) were taken as responsive variables [10].

Table 2: Factor combination as per central composite design

\begin{tabular}{|c|c|c|c|}
\hline $\begin{array}{l}\text { Formulation } \\
\text { no. }\end{array}$ & $\begin{array}{l}\text { Trial } \\
\text { no. }\end{array}$ & \multicolumn{2}{|c|}{ Coded factor } \\
\hline $\mathrm{X}_{1}$ & $\mathrm{X}_{2}$ & & \\
\hline $\mathrm{F} 1$ & 1 & -1 & -1 \\
\hline F2 & 2 & -1 & 0 \\
\hline F3 & 3 & -1 & +1 \\
\hline F4 & 4 & 0 & -1 \\
\hline F5 & 5 & 0 & 0 \\
\hline F6 & 6 & 0 & +1 \\
\hline F7 & 7 & +1 & -1 \\
\hline F8 & 8 & +1 & 0 \\
\hline F9 & 9 & +1 & +1 \\
\hline
\end{tabular}

Translation of coded levels in actual units

$\begin{array}{llll}\text { Coded level } & -1 & 0 & +1 \\ \mathrm{X}_{1}: \text { Carbopol 934P (mg) } & 60 & 80 & 100 \\ \mathrm{X}_{2}: \text { HPMC }(\mathrm{mg}) & 90 & 120 & 150\end{array}$

\section{Physical characterization of diltiazem tablets}

The formulated tablets were subjected to the following physical characterization studies. The drug content of each batch of the formulated tablets was determined in triplicate by UV-visible method at $237 \mathrm{~nm}$. The weight variation was determined based on 20 tablets using electronic balance. Mean tablet hardness was determined on six tablets from each batch using Monsanto tablet hardness tester. Friability was determined $(n=10)$ using Roche friabilator for $5 \mathrm{~min}$ at 25 
rpm, while thickness was determined using vernier calipers.

\section{Measurement of bioadhesive strength of tablets}

Gastric mucosa of goat was used as the model membrane for ex vivo measurement of bioadhesive strength. The mucosal membrane was excised by removing the underlining connective tissues. The mucosa was tied on the slide and the slide was fixed in the petri plate filled with distilled water and the petri plate was placed inside the left arm of the physical balance. The tablet was fixed on the left pan of the physical balance. The left arm was lowered until a tablet contact with the membrane was made. A contact force of $10 \mathrm{~g}$ was placed on the left arm for $5 \mathrm{~min}$. After $5 \mathrm{~min}$, the weight was removed from the left pan and the assembly was kept undisturbed. Weight was slowly added on the right hand side pan until the tablet just got detached from the membrane surface. The peak detachment force was recorded as a measure of bioadhesive strength [11].

\section{Swelling index}

Tablets were weighed $\left(\mathrm{W}_{1}\right)$ individually and placed in a USP XXII paddle method (apparatus 2) (model DS 8000, Lab India) containing $900 \mathrm{ml}$ $0.1 \mathrm{~N} \mathrm{HCl}$, stirred at $50 \mathrm{rpm}$ and maintained at 37 $\pm 0.5{ }^{\circ} \mathrm{C}$. At regular intervals, the tablets were removed from the dissolution apparatus, excess water removed carefully using filter paper and reweighed $\left(\mathrm{W}_{2}\right)$. Swelling index $(\mathrm{S})$ of each tablet was calculated by using following formula [12]:

$\mathrm{S}=\left(\mathrm{W}_{2}-\mathrm{W}_{1}\right) \mathrm{W}_{1}$

\section{In vitro drug release studies}

Dissolution studies were carried out on all the tablet formulations in triplicate, employing USP XXIl paddle method (Apparatus 2) at $50 \mathrm{rpm}$ and $37 \pm 0.5^{\circ} \mathrm{C}$, using $900 \mathrm{ml}$ simulated gastric fluid (SGF) $\mathrm{pH} 1.2$ without pepsin as the dissolution medium. Five $\mathrm{ml}$ of sample was withdrawn periodically at suitable time intervals and replaced with an equivalent volume of fresh dissolution medium. The withdrawn samples were analyzed by UV Spectrophotometer (UV 1800 Shimadzu) at $237 \mathrm{~nm}$. Drug release data obtained were analyzed using Zorel software [13] which has in-built provisions for applying the correction factor for volume and drug losses during sampling [14].
The drug release data were fitted to Korsemeyer-Peppas model (Eq 2) [15]. $\mathrm{Mt} / \mathrm{M} \infty=\mathrm{k}_{1} \mathrm{t}^{\mathrm{n}}+\mathrm{k}_{2} \mathrm{t}^{2 \mathrm{n}}$

where, $M_{t}$ is amount of drug released at time ' $t$ ', $\mathrm{M}_{\infty}$ is amount of drug released at an infinite time, $\mathrm{k}_{1}$ is the magnitudinal contribution of diffusion mechanism, $\mathrm{k}_{2}$ is the magnitudinal contribution of polymer relaxation mechanism, and $\mathrm{n}$ is the Fickian diffusion coefficient.

Based on phenomenological analysis, the type of release (i.e., whether Fickian, non-Fickian (anomalous) or zero order) was predicted [11]. $\mathrm{t}_{60 \%}$ value was calculated using Stineman interpolation option of the Graph 2.0 software (M/s Micromath Inc, St Louis, USA).

\section{Optimization data analysis and validation of optimization model}

The response variables which were considered for systematic optimization included $t_{60} \%, Q_{12}$ and BS. For the studied design, multiple linear regression analysis (MLRA) method was applied to fit full second-order polynomial equation with added interaction terms to correlate the studied responses with the examined variables using Design expert software version 8.0.5 (Stat-Ease, USA 45days trial version). The polynomial regression results were demonstrated for the studied responses. Finally, the prognosis of optimum formulation was conducted using a twostage brute force technique using MS-Excel spreadsheet software. First, a feasible space was located and second, an exhaustive grid search was conducted to predict the possible solutions. Six formulations were selected as the confirmatory check-points to validate RSM. The observed and predicted responses were critically compared. Linear correlation plots were constructed for the chosen eight optimized formulations. The residual graphs between predicted and observed responses were also constructed separately, and the percent bias (= prediction error) was calculated with respect to the observed responses [11].

\section{RESULTS}

\section{Physicochemical characteristics of the tablets}

Physical appearance, tablet hardness, friability, weight variation, and drug content uniformity of all formulations were satisfactory, as shown in Tables 3. It was observed that all the tablets showed acceptable physicochemical properties.

Trop J Pharm Res, December 2013;12 (6): 863 
Table 3: Some physicochemical properties of the bioadhesive tablets

\begin{tabular}{lcccc}
\hline $\begin{array}{l}\text { Formulation } \\
\text { code }\end{array}$ & $\begin{array}{c}\text { Mean hardness } \\
(\mathbf{k g})\end{array}$ & $\begin{array}{c}\text { Mean weight } \\
(\mathbf{m g})\end{array}$ & $\begin{array}{c}\text { Mean friability (\%) } \\
\text { F1 }\end{array}$ & $\begin{array}{c}\text { Drug content } \\
(\%)\end{array}$ \\
F2 & $4.5 \pm 0.051$ & $360.4 \pm 1.26$ & 0.65 & 98.53 \\
F3 & $4.5 \pm 0.054$ & $361.5 \pm 1.69$ & 0.68 & 98.38 \\
F4 & $4.6 \pm 0.083$ & $361.0 \pm 1.07$ & 0.64 & 98.46 \\
F5 & $4.4 \pm 0.054$ & $359.5 \pm 1.70$ & 0.56 & 99.42 \\
F6 & $4.6 \pm 0.10$ & $360.5 \pm 0.99$ & 0.58 & 99.78 \\
F7 & $4.5 \pm 0.12$ & $360.0 \pm 1.15$ & 0.68 & 97.32 \\
F8 & $4.6 \pm 0.10$ & $359.5 \pm 1.13$ & 0.69 & 100.52 \\
F9 & $4.8 \pm 0.081$ & $360.8 \pm 1.10$ & 0.45 & 99.02 \\
\hline
\end{tabular}

Table 4: Dissolution parameter for different bioadhesive tablets formulations

\begin{tabular}{lccccccc}
\hline $\begin{array}{l}\text { Formulation } \\
\text { code }\end{array}$ & $\mathbf{N}$ & $\mathbf{K}$ & $\mathbf{k}_{\mathbf{1}}$ & $\mathbf{k}_{\mathbf{2}}$ & $\begin{array}{c}\text { Rel12 hrs } \\
\mathbf{( \% )}\end{array}$ & $\mathbf{t}_{\mathbf{6 0} \%}$ & $\begin{array}{c}\text { Drug rel rate } \\
(\mathbf{m g} / \mathbf{h})\end{array}$ \\
\hline F1 & & & & & & \\
F2 & 0.4911 & 0.2590 & 1.2895 & 0.0132 & 94.54 & 4.95 & 8.298 \\
F3 & 0.5049 & 0.2539 & 1.2863 & 0.0147 & 91.04 & 4.66 & 8.047 \\
F4 & 0.5153 & 0.2452 & 1.2715 & 0.0177 & 90.79 & 4.75 & 7.875 \\
F5 & 0.5154 & 0.2397 & 1.2629 & 0.0178 & 87.60 & 5.19 & 7.764 \\
F6 & 0.5409 & 0.2198 & 1.2310 & 0.0240 & 86.25 & 5.16 & 7.397 \\
F7 & 0.5884 & 0.1876 & 1.1788 & 0.0351 & 84.86 & 5.81 & 6.880 \\
F8 & 0.6189 & 0.1621 & 1.1346 & 0.0426 & 84.56 & 7.14 & 6.396 \\
F9 & 0.6333 & 0.1519 & 1.1195 & 0.0445 & 82.39 & 7.66 & 6.177 \\
\hline
\end{tabular}

\section{Bioadhesive strength of tablets}

The bioadhesive strength of the tablets ranged between 7.6 to $21 \mathrm{~g}$, and increased with increase in the concentration of the polymer in the tablet; However, this effect was more pronounced for Carbopol.

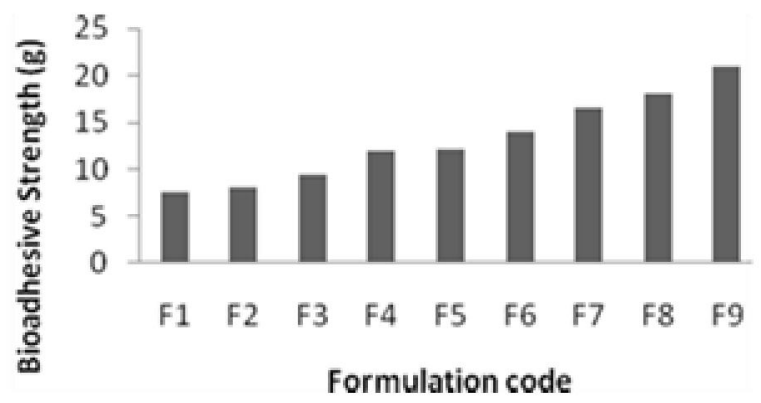

Fig 1: Bioadhesive strength of the formulations. Note: F1 - F9 are as defined in Table 1.

\section{In vitro drug release}

Table 4 enlists various dissolution parameters calculated for all the bioadhesive tablets. The value of diffusion exponent $(n)$ showed an increasing trend with increase in the content of either polymer. The values of Fickian diffusion constant $\left(k_{1}\right)$ varied between 1.104 and 1.289, while those of polymer relaxation constant $\left(k_{2}\right)$ varied between 0.0132 and 0.0489 . The values of $Q_{12 h}$ ranged between 79.74 and $94.54 \%$. An almost linear descending trend was observed in $\mathrm{Q}_{12 \mathrm{~h}}$ with an increase in CP 934P or HPMC fraction.

\section{Response surface analysis}

The coefficient of the polynomial equation (Eq 2) generated using MLRA for $Q_{12 h}, t_{60 \%}$ and $B S$ of the tablet, formed excellent fits to the data, with quite high value of $r^{2}$ ranging between 0.9898 and 0.999 .

$Y=\beta_{0}+\beta_{1} X_{1}+\beta_{2} X_{2}+\beta_{3} X_{1} X_{2}+\beta_{4} X_{1}^{2}+\beta_{5} X_{2}^{2}+$ $\beta_{6} X_{1} X_{2}{ }^{2}+\beta_{7} X_{1}{ }^{2} X_{2}$

Seven coefficients $\left(\beta_{1}\right.$ to $\left.\beta_{7}\right)$ were calculated representing $\beta_{0}$ as intercept, and $\beta_{3}$ to $\beta_{7}$ various quadratic and interaction terms.

Figs 2 to 4 show the various three dimensional response surface plots for the studied response properties, viz, $t_{60 \%}, Q_{12}$, and BS. Fig 2 Showed a linear increasing trends in the value of $t_{60 \%}$ with increase in the amount of either polymer but the 
influence of $\mathrm{CP}$ wass more significant than HPMC, indicating that the former has better release controlling properties than the latter. Hence, the higher levels of $\mathrm{CP}$ have to be complemented with lower levels of HPMC and vice-versa to maintain the value of $t_{60 \%}$ at a constant level.

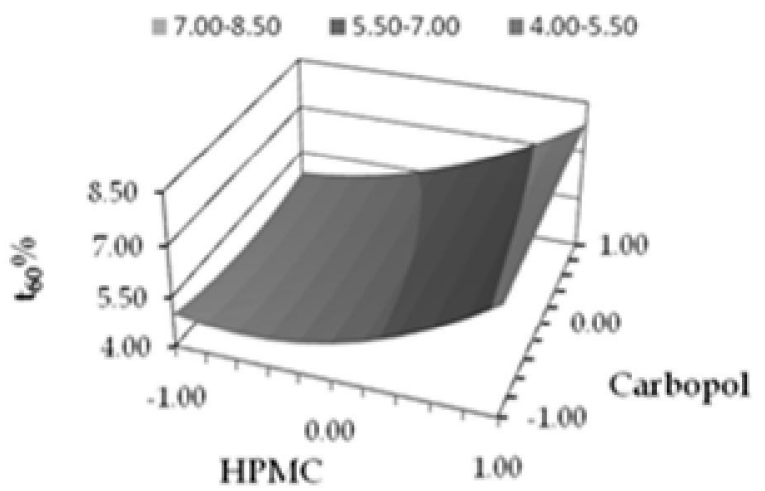

Fig 2: Response surface plot showing the influence of $\mathrm{CP}$ and HPMC on the value of $\mathrm{t}_{60 \%}$ of bioadhesive tablets of diltiazem hydrochloride.

Fig 3 shows a decline in the value of $Q_{12}$ with an increase in the concentration of each polymer. Nonlinear descending lines elucidate that the variation in $Q_{12}$ is a function of polymer levels, the effect of HPMC being less significant.

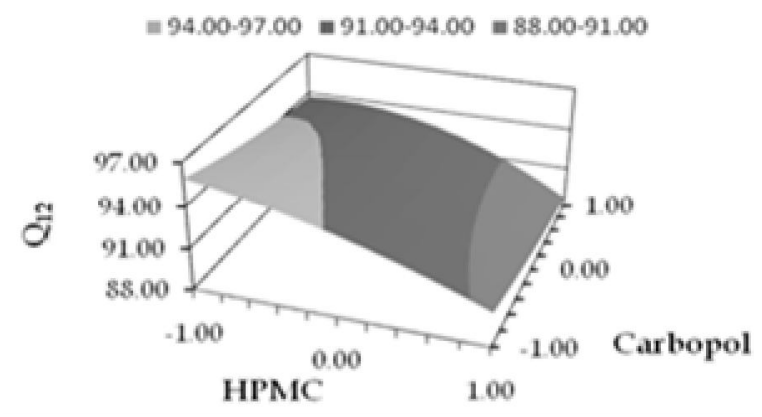

Fig 3: Response surface plot showing the influence of $\mathrm{CP}$ and HPMC on the value of $\mathrm{Q}_{12}$ of bioadhesive tablets

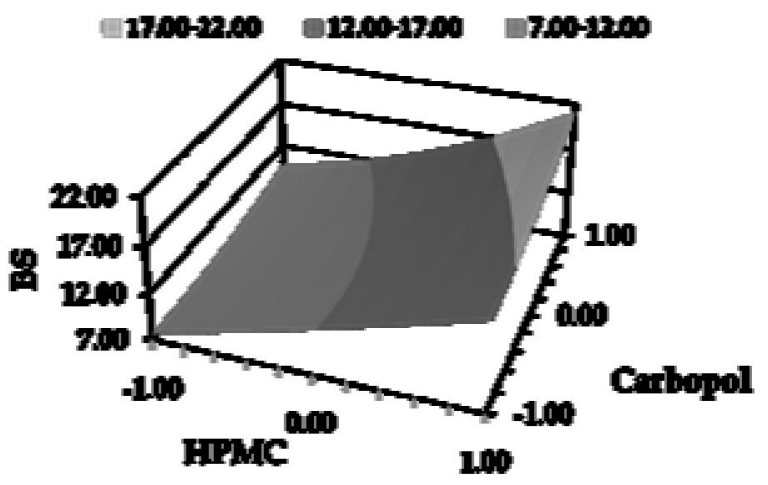

Fig 4: Response surface plot showing the influence of $\mathrm{CP}$ and HPMC on the value of bioadhesive strength of bioadhesive tablets of diltiazem hydrochloride.
Fig. 4 shows nearly linear ascending pattern for the values of bioadhesive strength as the content of either polymer increased in the formulation and the effect of $\mathrm{CP}$ is more prominent than HPMC. The maximum bioadhesive strength was observed at the highest levels of both the polymers. The results are in consonance with literature reports stating high contribution of carbomers in attainment of bioadhesive strength in hydrophillic matrices [10].

\section{Selection of optimized formulation}

The optimum formulation was selected by trading off various response variables and adopting the following maximizing criteria: $t_{60 \%}>$ $5.0 \mathrm{~h}, \mathrm{Q}_{12}>88 \%$, BS > 12. Upon comprehensive evaluation of grid searches, the formulation (CP $84 \mathrm{mg}$, HPMC $90 \mathrm{mg}$ ) fulfilled the optimal criteria of best regulation of the release rate and bioadhesive characteristics with $t_{60 \%}$ of $5.33 \mathrm{~h}$, $Q_{12 h}$ of $90.95 \%$ and bioadhesive strength of $12.79 \mathrm{~g}$. Thus, besides controlling drug release, the formulation has definite gastroretentive potential to retain the drug in the gastric environment and upper part of intestine.

\section{Validation of response surface methodology results}

Linear correlation plots drawn between predicted and observed responses, also demonstrated the high value of $r$, in the range of $0.991-0.987$ indicating excellent fit. Upon comparison of the observed responses with those of anticipated ones, the prediction error varied between -4.4 and 3.64.

\section{DISCUSSION}

The present investigation describes the development of an optimized gastric bioadhesive tablet formulation of diltiazem hydrochloride. A combination of ionic polymer (such as CP) and nonionic polymer (such as HPMC) were choosen because they are known to provide a formulation with controlled drug release and/or desired mucoadhesive properties [17].

Bioadhesive strength increased with increase in the content of either polymer, an observation that has previously been made [16]. Hydrogels are known to swell readily on contact with the hydrated mucous membrane [17]. Water sorption reduces glass transition temperature below ambient conditions, and hydrogels become progressively rubbery due to uncoiling of polymer chains and subsequent increased mobility of the polymer chains. The glassrubbery transition provides hydrogel 
plasticization, resulting in a large adhesive surface for maximum contact with mucin and flexibility to the polymer chain for interpenetration with mucin. Increasing the polymer amount may provide more adhesive sites and polymer chains for interpenetration with mucin, resulting in augmentation of bioadhesive strength. Although the maximum value of bioadhesive strength was attained at higher levels of both polymers and the effect carbopol on the bioadhesion was distinctly more pronounced than that of HPMC. The swelling of the formulation increased as the amount of either polymer increase in the tablet but the effect of HPMC on the swelling was more pronounced than that of carbopol due to the hydrophilic nature of the former.

The bioadhesive tablets showed values of $n$ ranging between 0.4911 and 0.6585 , indicating the non-Fickian release behaviour of all formulations. The values of $n$ showed increasing trend with increase in HPMC content, even at higher levels of Carbopol. on the other hand, the kinetic constant, $\mathrm{k}$, showed a decline with increase in the content of either polymer. Relatively much higher magnitude of Fickian diffusion constant, $k_{1}$ vis-à-vis the polymer relaxation constant, $\boldsymbol{k}_{\mathbf{2}}$ clearly showed that drug release was predominantly determined by Fickian diffusion, with a negligible contribution of polymer relaxation. This is in agreement with earlier findings that a mixture of HPMC and Carbopol resulted in the reduction of polymer viscosity due to reduced hydration $[11,18]$.

This reduction of viscosity could facilitate drug diffusion through polymer hydrogel. The overall rate of drug release tended to decrease with increase in the concentration of either HPMC or carbopol. Similarly, the values of $Q_{12 h}$ decreased with increase in polymer content. However, the values of $t_{60 \%}$ increased from 4.95 to $7.78 \mathrm{~h}$ for both polymers.

In Central Composite Design (CCD), all the factors are studied for all plausible combinations, as it is considered to be most efficient in estimating the influence of individual variables and their interactions, using minimum experimentation. Hence, CCD for two factors at three levels with $a=1$ was chosen. The high values of $r^{2}$ exhibited by the polynomial relationships vouched high statistical validity $(p<$ 0.001) of Equation 2 for fitting to the experimental data. The amounts of $\mathrm{CP}$ and HPMC had a positive influence on the values of coefficients of $t_{60} \%$, the effect being more apparent with HPMC. On the other hand, the positive effect of $\mathrm{CP}$ is vividly far more pronounced than that of HPMC in regulating the values of BS.

\section{CONCLUSION}

Suitable balancing between the levels of the two polymers (CP and HPMC) is imperative to attaining maximum prolongation of drug release and adequate bioadhesive strength. The bioadhesive nature of the formulation may prolong gastrointestinal $(\mathrm{Gl})$ residence time thus ensuring maximum absorption. The optimized formulation showed good controlled release and bioadhesive characteristics indicating the success of experimental approach employeded.

\section{REFERENCES}

1. Gambhire MN, Ambade KW, Kurmi, SD, Kadam VJ and Jadhav, KR. Development and In Vitro Evaluation of an Oral Floating Matrix Tablet Formulation of Diltiazem Hydrochloride. AAPS PharmSciTech 2007; 8: E1-E9.

2. Arora S, Ali J, Ahuja A, Khar RK, Baboota S. Floating drug delivery system: A Review. AAPS PharmSciTech 2005; 6: E372

3. Streubel A, Siepmann J, Bodmeier R. Drug delivery to the upper small intestine window using gastroretentive technologies. Curr Opin Pharmacol 2006; 6: 501-508.

4. Streubel A, Siepmann J, Bodmeier R. Gastroretentive drug delivery systems. Expert Opin Drug Deliv. 2006; 3: 217-233.

5. Chitnis VS, Malshe VS, Lalla JK. Bioadhesive polymerssynthesis, evaluation and application in controlled release tablets. Drug Dev Ind Pharm 1991; 17: 879-892.

6. Chueh HR, Zia H, Rhodes CT. Optimization of sotalol floating and bioadhesive extended release tablet formulations. Drug Dev Ind Pharm. 1995; 21: 1725-1747.

7. Arora G, Malik K, Singh I, Arora S, Rana V. Formulation and evaluation of controlled release matrix mucoadhesive tablets of domperidone using Salvia plebeian gum. J Adv Pharm Technol Res. 2011 2(3): 163-169.

8. Singh $B$, Kumar $R$, Ahuja N. Optimizing drug delivery systems using systematic "design of experiments «. Part I: fundamental aspects, Crit. Rev. Ther. Drug Carrier Syst 2005; 22: 27-105.

9. Chien YW. Novel drug delivery systems. 2nd edn. Marcel Dekker Inc., NY, 1992, 171-176.

10. Singh B, Pahuja S, Kapil R, Ahuja N. Formulation development of oral controlled release tablets of hydralazine: Optimization of drug release and bioadhesive characteristics. Acta Pharma 2009; 59: 1-13.

11. Singh. B, Rani A, Babita, Ahuja N, Kapil R. Formulation Optimization of Hydrodynamically Balanced Oral Controlled Release Bioadhesive Tablets of Tramadol Hydrochloride. Sci Pharm.2010; 78: 303-323.

12. Zeenath S, Gannu R, Bandari S, Rao YM. Development of gastroretentive systems for famotidine: in vitro characterization. Acta Pharmaceutica Sciencia 2010; 52: 495-504.

13. Singh B, Singh $S ; A$ comprehensive computer program for study of drug release kinetics from compressed matrices. Ind. J. Pharm. Sci. 1998; 60: 358-362. 
14. Singh B, Kaur $T$, Singh S; Correction of raw disolution data for loss of drug during sampling. Ind. J. Pharm. Sci 1997; 59: 196-199.

15. Korsemeyer RW, Gurny R, Doelker E, Buri P, Peppas $N$. Mechanism of solute release from porous hydrophillic polymers. Int J Pharm. 1983; 15: 2535.

16. Singh B, Chakkal S K, Ahuja N. Formulation and optimization of controlled release mucoadhesive tablets of atenolol using response surface methodology. AAPS Pharm Sci Tech 2006; 7: E2E10

17. Singh B, Ahuja N: Development of controlled-release buccoadhesive hydrophilic matrices of diltiazem hydrochloride: optimization of bioadhesion, dissolution, and diffusion parameters, Drug Dev. Ind. Pharm 2002; 28: 431-442.

18. Nur AO, Zhang JS. Captopril floating and/or bioadhesive tablets: design and release kinetics. Drug Dev Ind Pharm. 2000; 26: 965-969. 